\title{
The end of the fertility transition in the developing world
}

John Bongaarts

Population Council

Follow this and additional works at: https://knowledgecommons.popcouncil.org/departments_sbsr-pgy

Part of the Demography, Population, and Ecology Commons, Family, Life Course, and Society Commons, and the International Public Health Commons How does access to this work benefit you? Let us know!

\section{Recommended Citation}

Bongaarts, John. 2002. "The end of the fertility transition in the developing world," Policy Research Division Working Paper no. 161. New York: Population Council. 
0

$\mapsto$

$\infty$

•

\section{The End of the}

$>$

$\mapsto$

Fertility Transition in

a

the Developing World

㘴

John Bongaarts

0

$\approx$

$\varangle$

[I]

$\infty$

[T]

\&

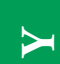

0

$\mapsto$

$\mapsto$

0

$\theta$

5 Y Y E A R S

2002 No. 161 


\title{
The End of the Fertility Transition in the Developing World
}

\author{
John Bongaarts
}

John Bongaarts is Vice President, Policy Research Division, Population Council.

Paper prepared for the UN Expert Group Meeting on "Completing the Fertility Transition," New York, 11-14 March 2002. 


\begin{abstract}
Fertility declines are now underway in many developing countries, and the focus of the debate about future fertility trends is shifting from the early to the later phases of the transition. This study examines patterns and determinants of fertility in the developing world using UN estimates of the total fertility rates for 143 developing countries from 1950 to 2000 . The main objective is to identify regularities in the past record that may provide clues to future trends.

Three key findings emerge from this analysis. First, the pace of fertility decline decelerates as countries reach the later stages of the transition. In the decade immediately following the transition onset, fertility usually declines rapidly and without interruption; but once fertility drops below about four births per woman, additional reductions occur, on average, at a substantially slower pace. Second, it is highly unlikely that developing countries will converge on replacement fertility of 2.1 children per woman as is often assumed in population projections. Past transition patterns suggest that a significant number of countries will likely stall above 2.1 for periods of up to decades or will approach low fertility at a very slow pace. Third, the future course of fertility depends crucially on progress in human development and on family planning effort. The recent experience of developing countries with relatively high levels of development suggests that life expectancy near 75 years combined with literacy near 95 percent is needed on average to reach replacement. Many countries are still far from these levels of human development and have weak family planning programs, thus making further progress through the transition difficult.
\end{abstract}

This material may not be reproduced without written permission from the author. 
Over the past four decades reproductive behavior has changed rapidly in much of the developing world. The average total fertility rate (TFR) has fallen by half from the traditional six or more to around three today, and contraceptive use-once rare-is now widespread. Between the early 1960s and the late 1990s the largest fertility declines occurred in Asia (-52\%) and Latin America (-55\%) and the smallest in sub-Saharan Africa (-15\%) (United Nations 2001). Differences among countries are even larger, with some completing the transition to replacement fertility in record time (e.g., China, Hong Kong, Singapore, South Korea), while others (mostly in sub-Saharan Africa) have seen little change in reproductive behavior.

These recent fertility declines have been more rapid and pervasive than had been expected. For example, although the medium variant projections prepared by the United Nations Population Division in the 1970s and 1980s correctly predicted widespread fertility declines by the 1990s, the actual levels in the 1990s were even lower than these projections indicated for some world regions. The substantial declines that took place in a few poor and largely agricultural countries such as Bangladesh were particularly unexpected. Demographers and social scientists have proposed a variety of explanations for why these fertility transitions have been so rapid, but there is no consensus and a sometimes contentious debate among competing theories continues in the demographic literature (see Bulatao and Casterline 2001 for a recent review).

With the spread of fertility decline through much of the developing world, the focus of the debate about future fertility trends is shifting from the early to the later phases of the transition. Until recently, only limited attention was given to understanding the determinants of reproductive behavior in developing countries with relatively low fertility. Conventional theories have little to say about the pace of fertility decline or the level at which fertility will stabilize at the end of the transition. It is often assumed, however, that ongoing declines will continue and that fertility near the replacement level of about two births per woman will prevail in the long run (for various perspectives see Caldwell 1982; Demeny 1997; National Research Council 2000). On this issue the UN has long incorporated the views of the demographic community in its projections. According to the medium variant of the most recent UN projections, virtually all subregions of the developing world will have ended their transitions by $2025-30$ with TFRs 
at or below 2.2. The only exceptions are expected to be sub-Saharan Africa and West Asia, where the TFR is projected to be still at 3.5 and 2.8 respectively (United Nations 2001). These assumptions about continued future fertility declines are critical to future trends in population size. Population growth over the next few decades will substantially exceed current projections if fertility declines are less rapid than now projected or if fertility at the end of the transition remains above the replacement level (Casterline 2001a; United Nations 2001).

This study examines recent trends and patterns in fertility in the developing world with particular emphasis on the later stages of the transition. The main objective is to identify regularities in the past record that may provide clues to future trends. Key issues examined include (1) the pace of fertility decline and changes in this pace over the course of the transition, and (2) the determinants of the fertility level at the end of the transition. We first examine the record of fertility change in the developing world over the past half-century. Next, to help explain observed transitions, we discuss the relationship between the TFR and socioeconomic indicators. In a concluding section we summarize the implications for future trends in fertility.

\section{PATTERNS OF CONTEMPORARY FERTILITY TRANSITION}

\section{Data}

This analysis of past fertility trends in the developing world relies on the most recent UN estimates of total fertility rates for 143 "less developed countries" (United Nations 2001). This data set provides estimates as five-year averages from 1950-55 to 1995-2000 and it includes all countries in Africa, Asia, and Latin America and the Caribbean (except the developed countries of Japan, Australia, and New Zealand). For the present study single-year estimates of the TFR were derived from these five-year averages with standard interpolation procedures. The onset of the transition is assumed to be the year in which the TFR drops to 5 percent below the maximum observed level between 1950 and 2000. This threshold for entry into the transition was chosen instead of the more common 10 percent decline used in many previous studies, to address a criticism of past practice by Casterline (2001a). He correctly notes that a transition may be 
underway for a number of years before a country reaches a 10 percent decline. The 5 percent decline threshold used here minimizes this problem. ${ }^{1}$

\section{Fertility levels in 1995-2000}

In 1995-2000 the weighted average of the TFR for the developing world as a whole is estimated at 3.1. This average is heavily influenced by the relatively low fertility of very large countries, in particular China with a TFR of 1.8. As a result, the unweighted average, which gives each country the same weight, is substantially higher at 4.1. The TFRs of individual countries vary widely from a low of 1.2 in Macao to a high of 8 in Niger. In the analysis below, the country is the unit of analysis and unweighted averages of the TFR and other demographic and socioeconomic indicators are used, because the focus is on understanding and predicting future fertility trends for countries.

Because the large majority of developing countries have not yet reached the end of their transitions, it is not possible to describe comprehensively the patterns that characterize entire transitions in the developing world. Of course some developing countries—about one in seven (21/143) — have already reached a TFR of 2.1 or lower, including China, Hong Kong, Singapore, Korea, and several Caribbean islands. Unfortunately, the experience of this selected set of countries is not representative of the developing world as a whole, and it therefore cannot be used to draw reliable conclusions about future transition patterns that will occur in other countries.

\section{Fertility patterns in countries with transitions starting in the 1960s}

Despite these limitations, valuable insights can be gained from partial transitions observed to date. For example, the record of countries that started their transitions in the 1960s provides a useful starting point for the discussion because these transitions have been underway for at least three decades. The fertility trends in this set of 38 countries are plotted in Figure 1. Three key features of these transitions are evident: 1) fertility is high until the transition begins; 2) once the transition gets underway fertility declines fairly rapidly and tends to continue doing so; 3 ) the pace of decline decelerates as coun- 
Figure 1 TFRs from 1953 to 1998 for countries with transition onsets in the 1960s

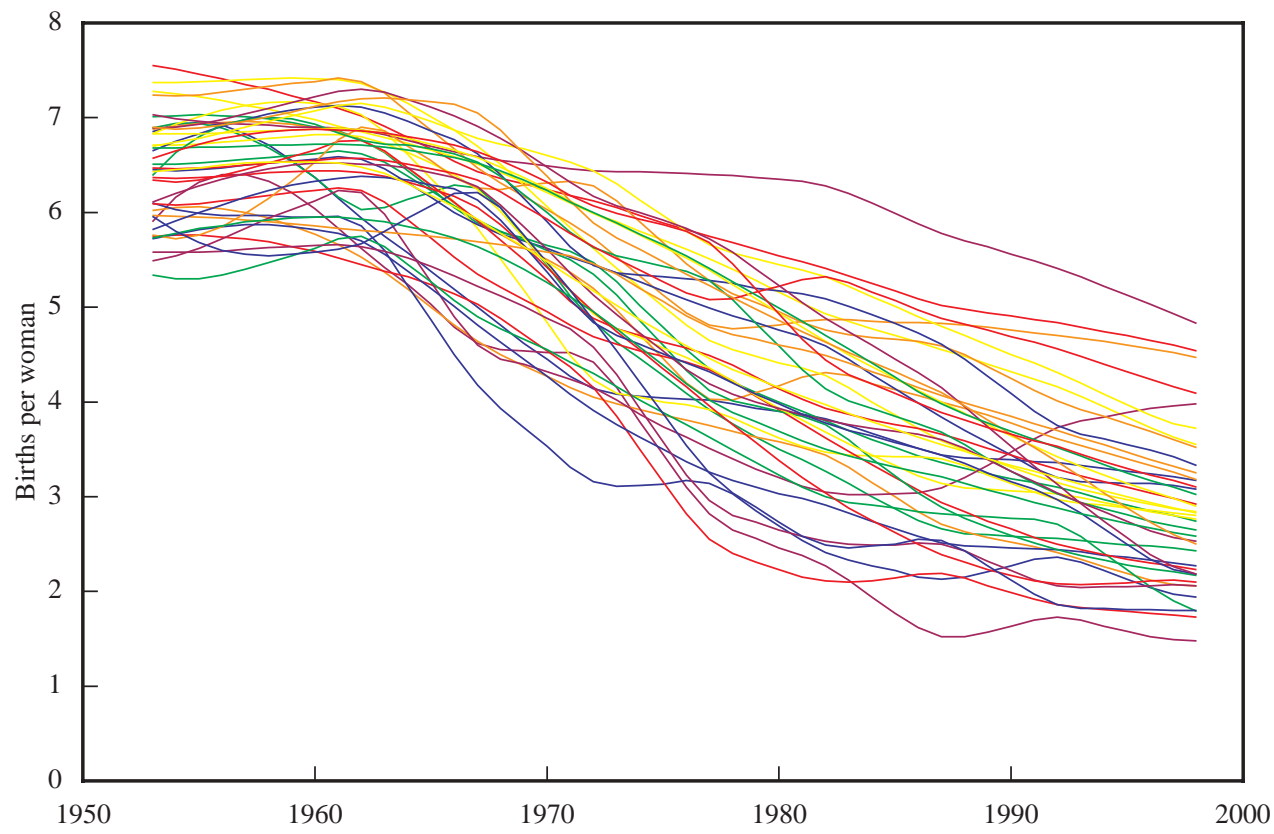

Source: United Nations 2001.

tries reach the later stages of the transition. In this set of countries the annual decline in the TFR averaged 0.15 in the early 1970s and only 0.06 in the $1990 \mathrm{~s}$.

These broad similarities aside, countries starting transitions in the 1960s diverge substantially in the level and pace of fertility at all stages of the transition. Particularly notable is the wide range in fertility in 1995-2000 from a high of 4.9 in Guatemala to 1.5 in South Korea. After three decades in transition, only eight of these 39 countries have a TFR at or below 2.1. Rapid declines to below replacement are the exception rather than the rule.

\section{Pace of fertility decline}

The question as to whether the pace of decline slows later in the transition can also be examined with more recent cross-sectional data from all developing countries. For each country the pace is measured as the annual change in the total fertility rate 
between one quinquennium and the next. For example, the TFR for the developing world as a whole dropped by 0.43 births between 1985-90 and 1990-95 (from 3.80 to 3.37). The annual pace of decline for the quinquennium starting in 1985-90 is therefore 0.086 (i.e., 0.43/5). Figure 2 plots the average pace for groups of countries with different levels of fertility. All observations after a country entered the transition are included. The relationship between the level of the TFR and its pace is plotted separately for the preand post-1975 periods. ${ }^{2}$

The main finding is that the pace of fertility change is positively associated with the level of fertility: the lower the TFR, the slower the pace of change. For example, before 1975 the average annual pace was 0.15 for countries with a TFR between 4 and 6 , but the pace was then only 0.04 for countries with a TFR between 2.0 and 2.5.

A comparison of this relationship between the pre- and post-1975 periods shows a significantly more rapid pace before than after 1975 for countries in earlier stages of

Figure 2 Annual pace of decline in TFR by level of TFR in transitional countries

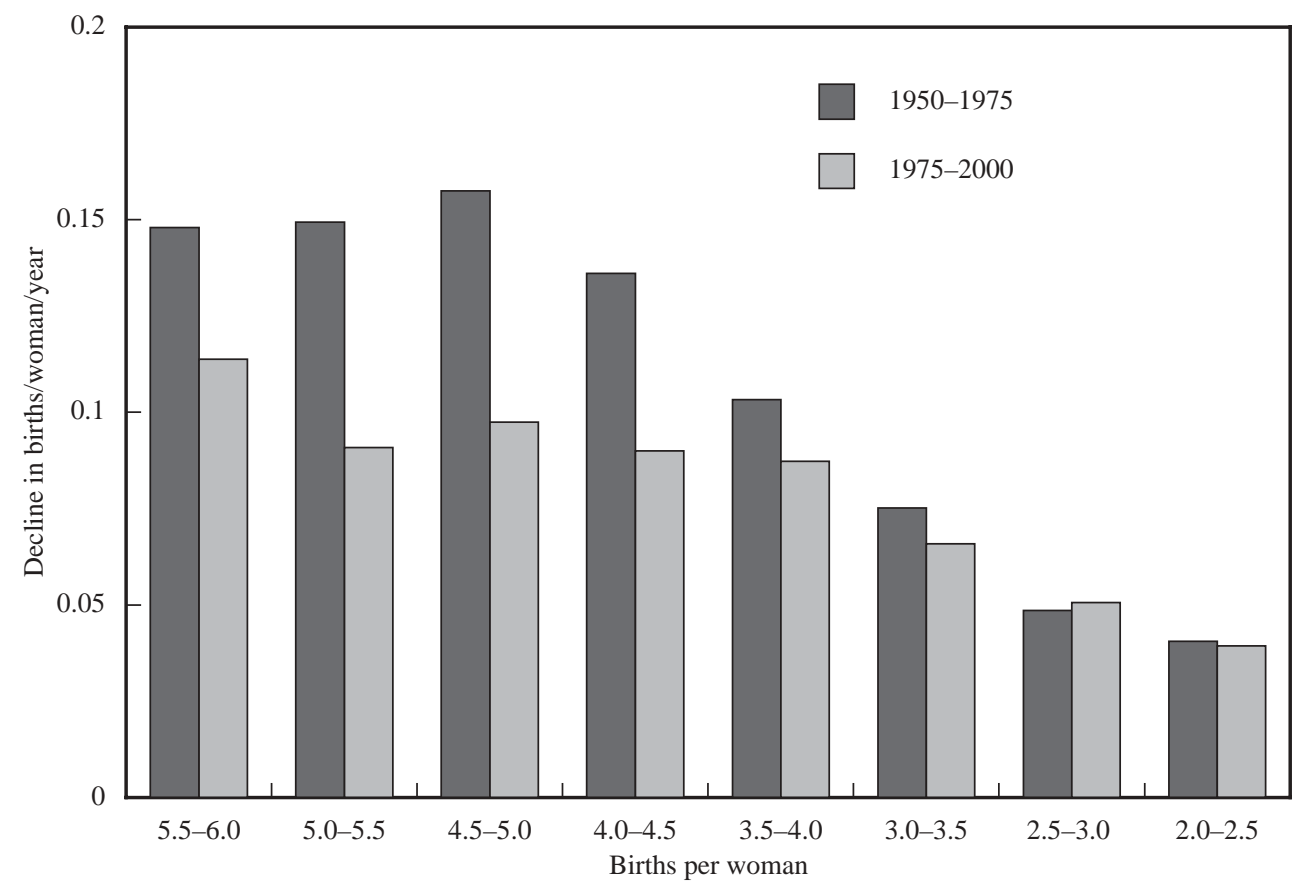

Source: United Nations 2001. 
the transition. ${ }^{3}$ For example, transitional countries with TFRs between 4 and 6 before 1975 experienced more rapid declines than countries with TFRs between 4 and 6 after 1975. ${ }^{4}$ In contrast, this difference between the pre- and post-1975 pace did not exist for countries with lower levels of fertility. Possible explanations are discussed below.

This cross-sectional evidence is consistent with the longitudinal pattern observed in the group of countries whose transitions began in the 1960s (see Figure 1). Both indicate substantial declines in the pace as the transition proceeds.

\section{The 1990s}

In the preceding analysis fertility trends were calculated from UN estimates for the past half-century. Unfortunately, estimates for the late 1990s in many countries are based on very limited direct information. Only a small number of developing countries have accurate vital statistics, and in a limited number of additional countries surveys are available after 1995. Information from the 2000 round of censuses was not yet available when the estimates published by the United Nations (2001) were made. In many countries the estimates for 1995-2000 are therefore obtained indirectly or are projections from earlier periods.

In the past few years results from a number of very recent DHS surveys have become available. These new data provide useful information on fertility trends during the 1990s. For present purposes a subset of DHS countries were selected in which two surveys were implemented during the 1990s and in which the TFR was below 4 in the early 1990s. ${ }^{5}$ Nine countries met these criteria and the two successive estimates of their TFRs are presented in the first two columns of Table 1. At the time of the first survey in the early 1990s the TFR ranged from 3.9 in Egypt to 2.5 in Kazakhstan and Turkey. At the time of the second survey in the late 1990s or 2000 the TFR had declined in most cases except in Turkey, where a slight rise was measured. The lowest TFR at the time of the second survey was 2.1 in Kazakhstan and the highest was 3.5 in Egypt.

The pace of decline between the two surveys averaged 0.048 births per woman per year. Notably, in five of the countries the pace was 0.3 or less, which is well below the pace observed in the 1980s. The transitions in these countries have slowed dramatically in the 1990s, or are close to stalling. 
Table 1 Estimates of total fertility rate and annual pace of TFR decline for countries with two DHS surveys between 1990 and 2000 and with TFR below 4 at the time of the first survey

\begin{tabular}{lccccc}
\hline & \multicolumn{2}{c}{$\begin{array}{c}\text { Observed TFR } \\
\text { from DHS surveys }\end{array}$} & & \multicolumn{2}{c}{ Pace of decline } \\
\cline { 2 - 3 } & Early 1990s & Late 1990s & & $\begin{array}{c}\text { DHS } \\
\text { estimates }\end{array}$ & $\begin{array}{c}\text { UN } \\
\text { estimates }\end{array}$ \\
\hline Bangladesh (1993/2000) & 3.4 & 3.3 & & 0.01 & 0.09 \\
Colombia (1990/2000) & 2.8 & 2.6 & & 0.02 & 0.04 \\
Dominican Rep. (1991/1996) & 3.3 & 3.2 & & 0.02 & 0.07 \\
Egypt (1992/2000) & 3.9 & 3.5 & & 0.05 & 0.09 \\
India (1993/1998) & 3.4 & 2.8 & & 0.11 & 0.08 \\
Indonesia (1991/1997) & 3.0 & 2.8 & & 0.03 & 0.09 \\
Kazakhstan (1995/1999) & 2.5 & 2.1 & & 0.11 & 0.06 \\
Peru (1992/2000) & 3.5 & 2.8 & & 0.09 & 0.09 \\
Turkey (1993/1998) & 2.5 & 2.6 & & -0.02 & 0.07 \\
Average & 3.1 & 2.9 & & 0.048 & 0.073 \\
\hline Source: DHS & & & & & 0.09 \\
\end{tabular}

Source: DHS first country reports and interpolation from United Nations (2001)

The last column of Table 1 indicates the pace of fertility decline as estimated by the UN for the period between the two DHS surveys in the 1990s. The average pace in the UN estimates for this set of countries is 0.073 , which is substantially higher than the 0.048 estimated from the DHS surveys. The cause of this difference is not clear and could be the result of errors in one or both DHS estimates. However, it is also possible that the UN has overestimated the pace of declines in some of these countries.

The three pieces of evidence reviewed here-trends in countries entering transitions in the 1960s, cross-sectional pace at different levels of fertility, and recent trends from DHS surveys - point to two conclusions. First, the pace of fertility decline usually decelerates as countries progress through their transitions. This is not a particularly surprising or controversial finding, but the cause of this trend is not obvious. Furthermore, the reduction over time in the pace in early-transitional countries is unexpected and calls for an explanation. Second, on the end point of the transition, the evidence is less clearcut, but convergence to 2.1 seems unlikely in the next quarter-century even for countries that are already in transition. It would be more plausible to assume considerable variation in levels of fertility at the end of transition in the next few decades, with some countries dropping below replacement and others stalling at higher levels. 


\section{RELATIONSHIP BETWEEN FERTILITY AND DEVELOPMENT INDICATORS}

To obtain a better understanding of contemporary patterns of fertility transition, it is useful to examine the relationship between fertility and socioeconomic indicators. The following five conventional indicators are used for this purpose: life expectancy at birth, percent literate among adults, real GDP per capita (log) adjusted for purchasing power, percent of population in urban areas, and percent of labor force in agriculture (United Nations 2001; World Bank 2000; Heston et al. 1995). Data for most of these variables are available from 1960 to the early 1990s, and the analysis below is therefore confined to this period. ${ }^{6}$ All countries for which these variables are available are included in the analysis except the major oil exporters (Brunei, Libya, Oman, Saudi Arabia, and the United Arab Emirates), whose highly unusual development experience is not examined. In addition, crisis years defined by very large and sudden changes in life expectancy are excluded (e.g., Cambodia in the 1970s). ${ }^{7}$

Figure 3 plots the relationship between TFR and life expectancy and includes all observations (137 countries, with multiple observations per country from 1960-65 to 1990-95). The simple correlation between these variables is a highly significant -0.79 . Correlations between the TFR and the other four development indicators (not shown) are also highly significant and in the expected direction although somewhat smaller in size: percent literate, -0.73 ; GDP per capita, -0.68 ; percent urban, -0.63 ; and percent of labor force in agriculture, 0.69 .

The data in Figure 3 also demonstrate that the relationship between TFR and life expectancy is nonlinear. At the lowest levels of life expectancy the TFR is high and there is no significant correlation between the two. In contrast, at high levels of life expectancy the TFR is strongly and inversely associated with life expectancy. Similar nonlinear patterns of association exist for the other development indicators. To shed light on this changing relationship we examine in greater detail the successive phases of the transition. Three phases are distinguished below: 1) pretransition, covering all observations before the TFR reaches the 5 percent decline threshold, 2) transition onset and early transition, covering the first decade after the year in which the threshold is 
Figure 3 Relationship between TFR and life expectancy for 137 developing countries with observations from 1960-65 to 1990-95

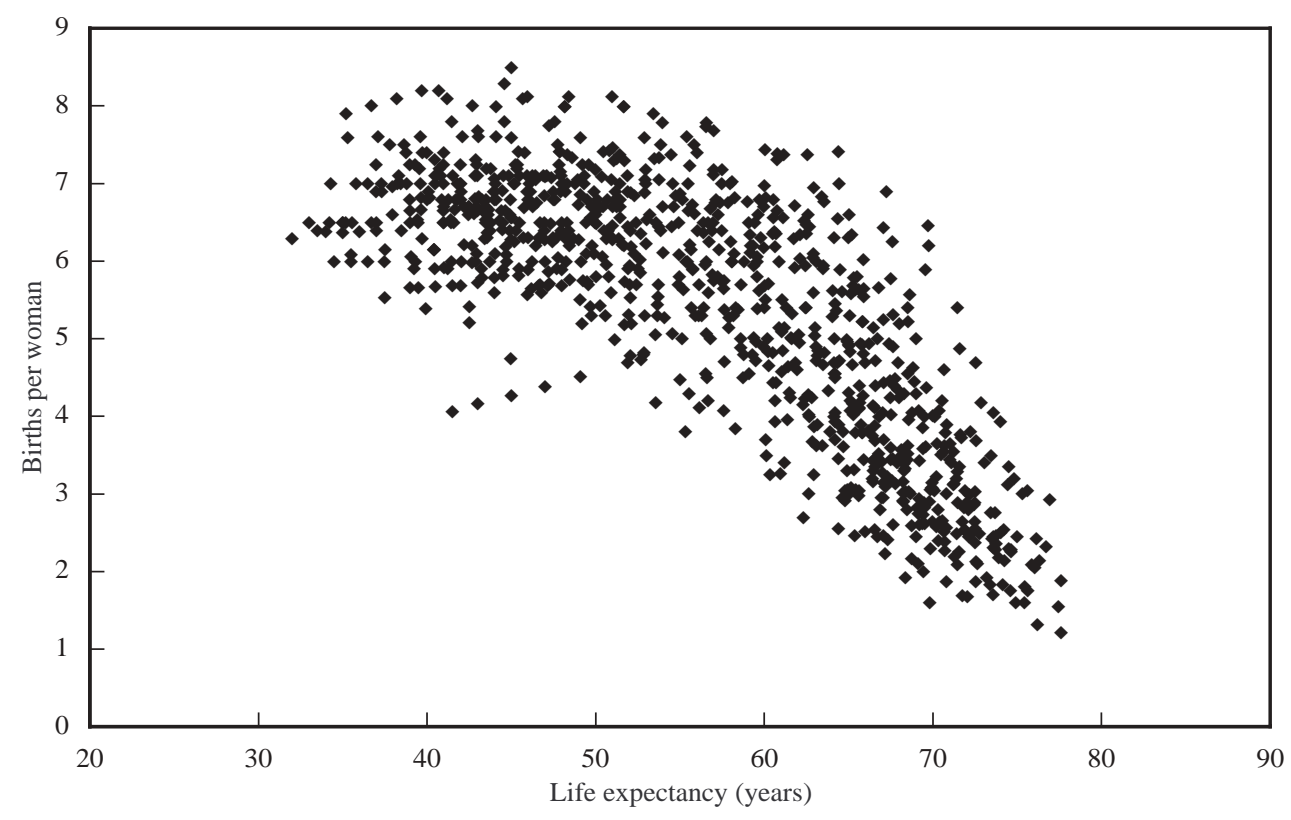

Source: See text.

reached, and 3) mid and late transition, the remaining period with more than ten years after transition onset.

\section{Pretransition}

In 1960-65 the large majority of developing countries had not yet entered the transition. The average TFR in these pretransitional countries in the early 1960s was 6.7 with a standard deviation of 0.6. Regional averages were similar for Asia (6.5), Latin America (6.6), and sub-Saharan Africa (6.7), but slightly higher in the Middle East/ North Africa (7.1). Regression analysis indicates no significant effects on fertility of development indicators in countries with the lowest levels of development. ${ }^{8}$ Although countries vary in their level of pretransitional fertility, there is usually little trend up or down before the transition starts. The TFR can therefore be considered largely unre- 
sponsive to changes in development until the transition begins. This pattern of fertility is consistent with the existence of natural fertility, defined as the fertility that prevails when couples do not consciously limit the size of their families (Cleland 2001; Henry 1961; Knodel and van de Walle 1979). Fertility surveys in pretransitional countries have confirmed that only a very small proportion of couples practice contraception (Curtis and Neitzel 1996), and differences in fertility are caused primarily by differences in proximate determinants other than contraception (Bongaarts and Potter 1983). This issue is not discussed further because this study focuses on the later phases of the transition.

\section{Transition onset}

The transition has begun in 123 of the 137 developing countries included in this analysis. The year of onset varied widely: 23 countries entered their transition before 1960, 38 in the 1960s, 32 in the 1970s, 23 in the 1980s, and 7 in the 1990s. The remaining 14 countries will presumably also enter the transition eventually. As shown in Figure 1 , the onset of a transition typically represents a break from the past, with the pace of fertility decline sharply higher after than before the onset. In countries for which time series of contraceptive use are available, a rise in contraceptive use from very low levels coincides with the onset of the transition (Bongaarts and Johansson 2002; United Nations 1999).

The transition onset occurs after a country's level of development has risen for some time. On average in the year of onset, life expectancy was 54.7 years, percent literate 52.8, GDP per capita $(\log ) 3.14$, percent urban 32.8, and percent of labor force in agriculture 57.5 (see last column of Table 2). There is, however, no well-defined threshold of development that signals the start of a transition. In fact, levels of development at time of onset vary considerably historically in Europe and in contemporary developing countries. One cause of this variation is that the level of development at the time of onset appears to have declined over time (Bongaarts and Watkins 1996). This trend is also evident in Table 2, which presents averages for development indicators in the year of transition onset for groups of countries entering the transition in different decades from the 1960 s to the 1990s. For example, the average life expectancy in the year tran- 
Table 2 Average levels of development indicators in year of onset of transition by decade in which transition occurred

\begin{tabular}{lccccc}
\hline & $\mathbf{1 9 6 0 s}$ & $\mathbf{1 9 7 0 s}$ & $\mathbf{1 9 8 0 s}$ & $\mathbf{1 9 9 0 s}$ & All \\
\hline Life expectancy (years) & 57.7 & 54.1 & 51.1 & 48.7 & 54.7 \\
Literacy (\%) & 61.6 & 52.2 & 44.9 & 41.3 & 52.8 \\
GDP per capita (log \$) & 3.21 & 3.19 & 3.03 & $\mathrm{a}$ & 3.14 \\
Urban population (\%) & 37.2 & 34.3 & 25.2 & 27.0 & 32.8 \\
Labor force in agriculture (\%) & 50.3 & 57.1 & 68.2 & $\mathrm{a}$ & 57.5 \\
\hline
\end{tabular}

${ }^{a}$ Fewer than 5 observations

Source: See text.

sitions started was 57.7 years in the 1960s, but it declined to 54.1 in the 1970s, 51.1 in the 1980s, and 48.7 in the 1990s. Similarly, this average declined over time for percent literate, GDP per capita, and percent urban and rose for percent of labor force in agriculture. These effects are statistically significant for life expectancy, percent literate, and GDP per capita. ${ }^{9}$ Apparently, the later in time a transition starts, the lower the average development level at transition onset. It is unclear whether this trend will continue into the future.

\section{Early transition phase}

Once a transition starts, it tends to continue. Reversals and plateaus are very unusual in the early phases of the transition. The pace of decline is typically faster immediately after onset than in any other phase of the transition. An earlier study of these trends by Bongaarts and Watkins (1996) concluded that the initial pace of change in fertility was not associated with the pace of development. However, the pace of initial decline was positively associated with the level of development at the time of onset. These findings are confirmed here with a more complete data set. For example, Figure 4 plots the annual decline in TFR in the decade after transition onset by level of life expectancy at the time of onset. The significant positive association between these variables indicates that when a country begins its transition at a low life expectancy, it has on average a slower initial pace of fertility decline than a country with a high life expectancy at the time of onset. Similar significant effects on the initial pace of decline are found for level of literacy and percent of labor force in agriculture at the time of onset. ${ }^{10}$ 
Figure 4 Pace of TFR decline in decade after transition onset by life expectancy in year of onset

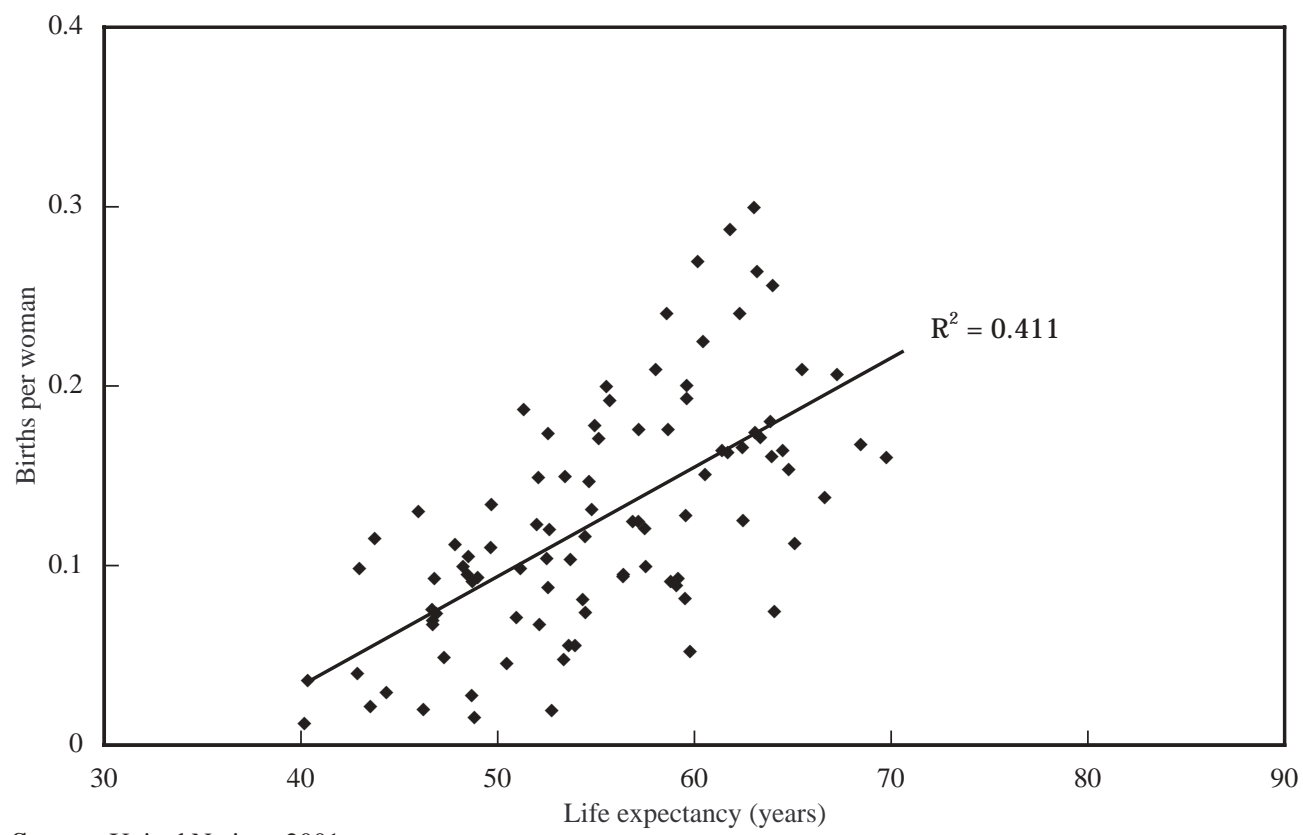

Source: United Nations 2001.

These findings are consistent with the previous observation (Figure 2) that the pace in the initial transition stage has declined over time. Apparently, in later decades countries enter the transition at lower levels of development, but for this reason the initial pace is lower than for countries that entered the transition in earlier decades at higher levels of development.

The key features of the early phases of the transition are summarized in Figure 5, which presents stylized plots of typical trends in fertility for three groups of countries with transitions starting in the 1960s, 1970s, and 1980s. The solid lines represent the approximate observed average fertility trends for these three groups. The dashed lines represent the simulated fertility trends that would have been observed if the groups starting in the 1970s and 1980s had been exposed to the same average development level at transition onset and had experienced the same initial pace of decline as observed in the group starting in the 1960s. For example, line A plots the approximate observed average trend for countries starting their transitions in the 1970s. If the transitions in this 
Figure 5 Approximate fertility trends in observed and simulated transitions for groups of countries with transition onset in the 1960s, 1970s, and 1980s

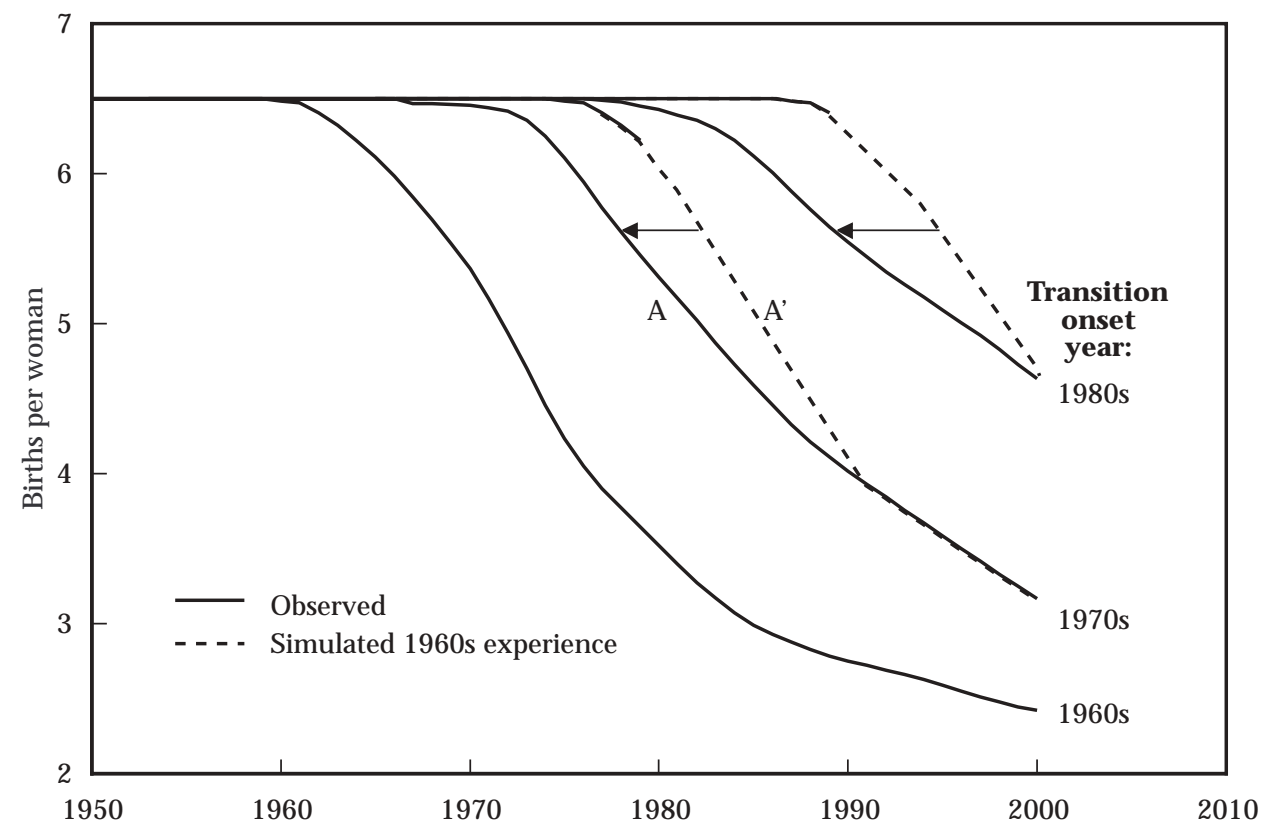

Source: See text.

group had started at a level of development and with a pace that was typical for the 1960s, their transitions would have started later (say around 1980 when their level of development would have been higher than it was in the 1970s) and at a faster pace than they actually experienced (compare dashed line A' with solid line A). Similarly, if the populations with transition onsets in the 1980s had followed average patterns of the 1960s, their transitions would have started considerably later (say in the 1990s) and at a faster pace. Because the relatively early onset of transitions in the 1970s and 1980s is associated with a slower initial pace, over time the observed fertility trends in these groups of countries tend to converge to the levels that would have been observed without these effects (i.e., the solid and dashed lines in Figure 5 converge). As a result, these effects are important early in the transition, but their role diminishes over time.

An explanation for these at first puzzling trends in fertility in the early phases of the transitions is likely to be found in diffusion and social interaction processes, which 
interfere with a smooth adjustment of fertility to changing socioeconomic circumstances. Diffusion refers here to the spread of information, ideas, and behaviors among individuals, communities, and countries; and social interaction refers to the fact that reproductive attitudes and behaviors of individuals can be influenced by the attitudes and behaviors of others. An extensive literature exists on this subject (Bongaarts and Watkins 1996; Caldwell 2001; Casterline 2001a, 2001b; Cleland 2001; Cleland and Wilson 1987; Knodel and van de Walle 1979; Kohler 2001; Montgomery and Casterline 1996; National Research Council 2001; Watkins 1986, 1987) and only a brief outline of the main points is given here:

- The first key element of an explanation is an initial resistance to reproductive change in pretransitional societies with natural fertility. Traditional norms and values tend to support large families and to discourage the deliberate limitation of family size through contraception. This resistance to change leads to a growing gap between actual and desired family size when child mortality and desired family size decline with development, thus building a potential for future fertility decline.

-As development proceeds, the desire for reproductive change becomes sufficiently large and widespread that a few innovators adopt contraception-typically first among highly educated and urban couples. Once begun, reproductive change spreads rapidly as diffusion and social interaction processes reinforce rather than inhibit such change. The cost of contraception (broadly defined to include social costs) drops. In addition, diffusion and social interaction can alter couples' evaluation of the costs and benefits of childbearing, thus reducing fertility preferences. The combination of a substantial (and growing) existing demand for and a reduction in the cost of contraception results in a "sharp acceleration in fertility decline that is a kind of 'catching up' as pentup desires for limiting fertility are released" (Casterline 2001a: 34). This initial fertility decline is typically more rapid the more developed a society is at the time of onset because higher levels of development are associated with lower desired family size and hence with larger gaps between actual and desired behavior. And the more developed a country, the more extensive the channels for social interaction and diffusion of innovative ideas, information, and attitudes.

- Finally, social interaction among countries is an important cause of the reduction over time in the average development level at transition onset. The fact that some 
countries in the world or in a region have already entered a transition tends to facilitate the onset in other countries that are still pretransitional. Interaction among countries occurs through many channels including trade, exchange of technology, labor migration, tourism, and the media, all of which facilitate the spread of ideas and information about the means for and desirability of family limitation. A large international effort to implement family planning programs in many developing countries has also played an important role because these programs give couples access to and information about birth control methods.

While this general explanation for observed transition patterns is plausible, many details remain to be settled and further research is needed to confirm its validity.

\section{Mid and late transition phases}

In the later phases of the transition, fertility behavior is more consistent with the expectations of most demographic and economic theories of fertility (Becker 1991; Bulatao and Lee 1983; Caldwell 1982; Easterlin 1975; Notestein 1953). According to these theories, the main driving force of fertility transitions is a rise in the cost of children and a decline in their value to parents as traditional agricultural societies are transformed into modern industrial ones. This shifting balance of costs and benefits leads to declines in desired family size and, with the implementation of these preferences through contraception and abortion, to lower fertility. As a consequence, fertility levels are inversely related to development indicators.

This conclusion is supported by the regression results presented in Table 3. Five development indicators and year of observation are the explanatory variables for the level of the TFR. ${ }^{11}$ All observations from 1960-65 to 1990-95 in which a country is more than a decade past the year of transition onset are included. The main findings from this regression are: ${ }^{12}$

1) The coefficients for life expectancy and literacy are highly significant and negative, implying that these development indicators are inversely related to fertility.

2) The effects of GDP per capita, percent urban, and percent of labor force in agriculture are not significant.

3) Regional dummy variables for Asia, Latin America, and the Middle East are not significantly different from zero (Africa is reference region). 
Table 3 Regression results (OLS) for total fertility rate and development indicators for countries in mid or late transition (more than 10 years past transition onset)

\begin{tabular}{lccc}
\hline Variable & Coefficient & t statistic & Significance level \\
\hline Life expectancy & -0.104 & -6.28 & 0.000 \\
Percent literate & -0.015 & -3.02 & 0.003 \\
GDP per capita (log) & -0.157 & -0.45 & 0.650 \\
Percent urban & 0.002 & 0.48 & 0.631 \\
Percent labor in agriculture & 0.004 & 0.68 & 0.498 \\
Region = Asia & -0.150 & -0.63 & 0.527 \\
Region = Latin America & 0.433 & 1.92 & 0.056 \\
Region = Middle East & 0.445 & 1.71 & 0.089 \\
Year = 1960-69 & 0.341 & 1.56 & 0.120 \\
Year = 1970-79 & 0.200 & 1.22 & 0.222 \\
Year =1980-89 & 0.175 & 1.32 & 0.187 \\
Constant & 11.57 & 8.10 & 0.000 \\
$\mathrm{R}^{2}=0.60$ & & & \\
\hline
\end{tabular}

Source: See text.

4) None of the dummy variables for year of observation is significant. This suggests that the relationship between fertility and development does not vary with time. (The fact that the coefficients for these dummy variables are positive and decline with time leaves open the possibility of a slight downward drift over time in the TFR for given levels of the development indicators.)

These findings support the view that human development (in particular, improvements in health and education) is the most critical determinant of progress through the fertility transition (Sen 1999). In fact, it is possible for fertility in poor populations to drop to the replacement level provided literacy and life expectancy are high. Well-known examples of this trend are Sri Lanka and the state of Kerala in India. It should be noted that the two human development indicators included in this analysis (literacy and life expectancy) were selected because long time series were available for a large number of countries. It is possible that closely related variables such as child mortality or level of school enrollment are equally or even more important determinants of fertility, but this issue is not examined here in part owing to lack of data.

Reaching near-replacement fertility apparently requires high levels of human development in most countries. To illustrate this point, consider the set of developing countries that had life expectancy above 70 years combined with literacy above 90 percent in the late 1990s. Only 20 out of 137 countries met these criteria. In this small 
group of countries with high human development the TFR averaged 2.24 (i.e., near replacement), average life expectancy was 74.5 years, and average literacy was 94.3 percent (see Table 4, first column). The finding that the fertility-development relationship has not significantly shifted since the 1960s suggests that similarly high levels of life expectancy and literacy will likely be needed to reach TFRs near replacement in the future. Because the large majority of developing countries fall well short of these levels of human development, considerable progress will have to be made before near-replacement fertility becomes widespread.

It is of interest to compare these statistics for countries with high human development with the same statistics for countries with below-replacement fertility in the late 1990s. Twenty-one countries had a TFR of 2.1 or less and their TFRs averaged 1.76. As shown in the last column of Table 4 this low fertility was accompanied by about the same levels of life expectancy and literacy as in the group of countries with high development. However, fertility differed by 0.5 births - 1.76 vs. 2.24 - between the two groups of countries. This difference is largely explained by the nature of countries with low fertility. Populations that now have below-replacement fertility are a select group, in which fertility is on average more responsive to socioeconomic changes than is the case in countries with the same levels of development that have not reached the end of the transition. Their experience is not a useful guide for future trends in other developing countries. In particular, it is not possible to conclude that all or most developing countries will closely follow the trajectory of this small, selected subset of countries.

One reason why reaching replacement fertility is difficult is that it requires a high level of birth control. The TFR at any point in time equals the sum of wanted and unwanted fertility. Even if wanted fertility declines to 2, a fairly typical level in developing

Table 4 Average levels of TFR, life expectancy, and literacy in countries with high human development and in countries with low fertility, 1995-2000

\begin{tabular}{lcc}
\hline & $\begin{array}{c}\text { 20 countries with } \\
\text { high human development } \\
\text { (life expectancy }>\mathbf{7 0} \text { and literacy }\end{array}$ & $\begin{array}{c}\text { 21 countries with } \\
\text { low fertility } \\
\text { (TFR } \leq \mathbf{2 . 1})\end{array}$ \\
\hline TFR (births per woman) & 2.24 & 1.76 \\
Life expectancy (years) & 74.5 & 73.5 \\
Literacy $(\%)$ & 94.3 & 93.0 \\
\hline
\end{tabular}

Sources: United Nations 2001, World Bank 2000. 
countries approaching the end of the transition, the overall level of fertility will be higher because of unwanted childbearing. According to DHS surveys the unwanted TFR ranges from a few tenths of a birth (e.g., in Indonesia) to nearly two births per woman (e.g., in Bolivia) (Bankole and Westoff 1995). Ready access to family planning methods and abortion services is needed to achieve low levels of unwanted childbearing. Reaching replacement fertility requires a low desired family size and excellent control of fertility. In the absence of either of these conditions, fertility will remain above replacement.

It should be noted that any analysis of levels and trends in the TFR can be confounded by so-called tempo effects, which are caused by a change in the timing of childbearing (Bongaarts and Feeney 1998; Bongaarts 1999). It is likely that these tempo effects exist in many developing countries because the mean age at marriage and at first birth is rising, but a full discussion of this issue is beyond the scope of the present study.

The role of family planning programs is not explicitly examined in the regression summarized in Table 3 because reliable time series of program effort are not available for the 1960s and 1970s. A separate regression (not shown) restricted to observations in the early 1990s and with program effort score added as an explanatory variable yielded a significant effect for program effort. This result confirms earlier studies which found that these programs reduce fertility by assisting couples in implementing their fertility preferences (Bongaarts 1997; Tsui 2001). A high-quality family planning program can move a country closer to replacement fertility than would be expected from its level of development alone. An example of this effect is found in Bangladesh, which has a TFR of 3.3 despite scoring relatively low on most development indicators.

This review of the effects of development on fertility leads to the following tentative conclusions. Although a decline in the demand for children is the main driving force of the transition, each of the transition phases is characterized by a different process. In the least-developed pretransitional societies, fertility is natural and initially unresponsive to changes in development. In contrast, in the years immediately following transition onset, fertility change is usually most rapid as diffusion and social interaction processes reduce the cost of contraception and facilitate the establishment of new reproductive attitudes and behaviors. These processes apparently have their main impact early in the transition and as a result the pace of decline slows over time. Finally, as the transition proceeds to its later stages, fertility is closely associated with development 
indicators, and continued fertility decline usually requires further development. This does not imply that social interaction and diffusion effects are absent later in the transition, but rather that such effects are then closely tied to development.

\section{Projecting Future Trends in Fertility}

The past record of fertility transitions provides the main basis for making fertility projections. Existing projections by the United Nations Population Division and other agencies such as the World Bank (2000), IIASA (Lutz 1996), and the U.S. Census Bureau (1999) generally assume that pretransitional countries will enter the transition in the near future and that, once underway, a transition will continue until the TFR reaches 2.1 or less. The specifics of how these projections are made in each country are complex and are not examined here, but a brief comment on the most widely used projections by the UN is in order.

The UN's methodology for projecting fertility in the large majority of developing countries that have not yet completed their transition consists of three steps. First, available data from surveys, censuses, and other sources are analyzed to obtain an estimate of the TFR for the most recent five-year period (i.e., 1995-2000 for the 2000 revision). Next, the target year in which fertility reaches 2.1 is determined. This year is estimated by taking into account "a range of socioeconomic factors, such as population policies and programs, adult literacy, school enrollment levels, economic conditions (gross domestic product or gross national product per capita), infant mortality and nuptiality, as well as historical, cultural and political factors" (United Nations 1998). Finally, linear interpolation between 1995-2000 and the target year yields the projected trajectory for the TFR (except in countries that were still pretransitional in 1995-2000, which are assumed to initiate a decline after 2005). The advantage of this procedure is that it is simple to apply in a large number of countries. For a small number of countries the UN makes more detailed assumptions and the resulting trajectory is nonlinear.

The main features of the UN projections of the TFR by country are evident from an inspection of Figure 6, which plots expected trends from 2000 to 2050 for all developing countries with above-replacement fertility. A comparison of these trajectories with the pattern experienced in the past by countries that entered the transition in the 1960s (see Figure 1) reveals two main differences. First, after three decades of transition expe- 
Figure 6 Projections of TFR for developing countries, UN medium variant 2000-50

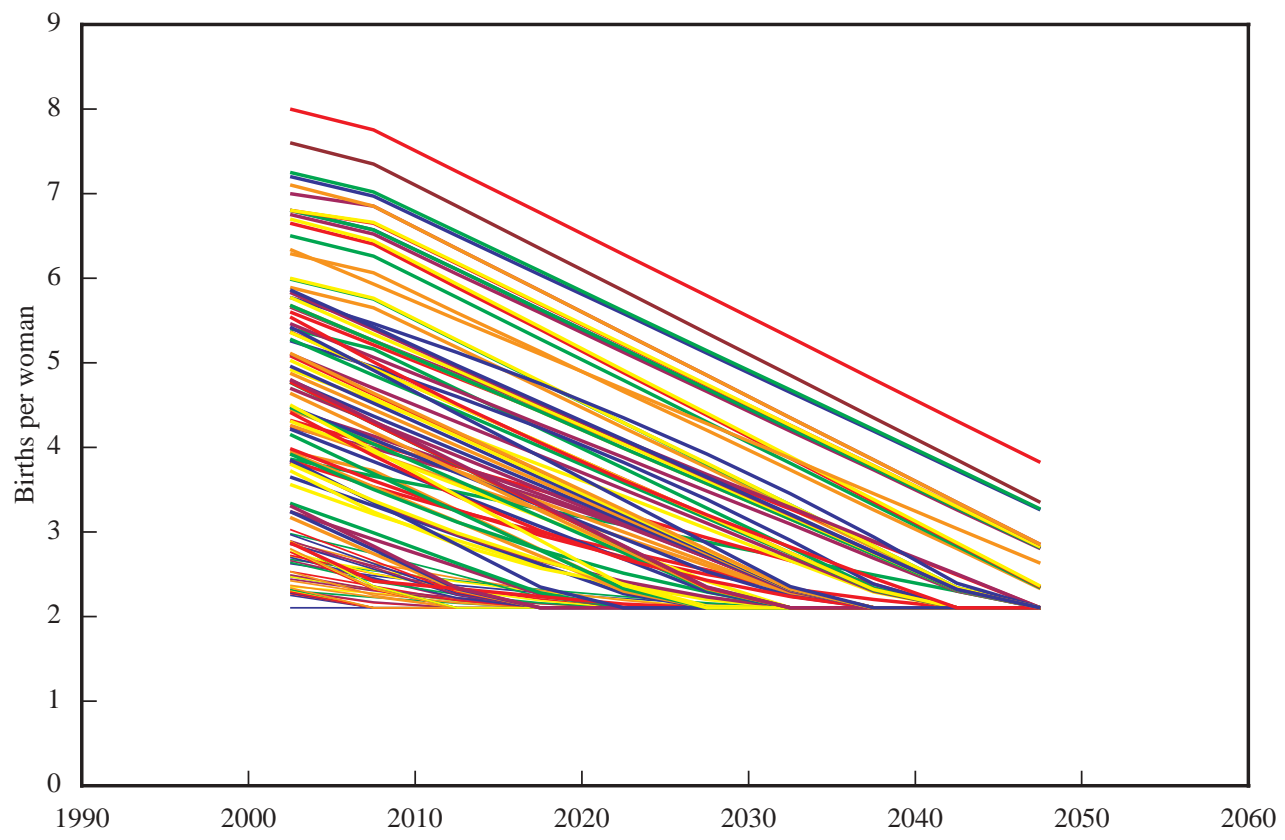

Source: United Nations 2001.

rience, observed past fertility levels and trends are considerably more diverse than is implied by the UN assumption of convergence to 2.1. Although the transitions plotted in Figure 1 are not yet complete, it seems likely that substantial differences in fertility levels will remain in the future. Some countries will end the transition below 2.1, while others will end above 2.1. Although it is difficult to predict future fertility levels at the end of ongoing transitions, it is reasonable to assume that fertility will vary with socioeconomic conditions. Second, as shown in Figures 1 and 2 the trend in fertility during the transition is not linear. Instead of being constant (as the UN assumes for most countries), the observed pace of past transitions has been lower in the later than in the earlier phases of the transition.

The medium variant of the UN projections expects the average TFR of developing countries to decline from 4.1 in 1995-2000 to 2.8 in 2020-25. It also expects a large number of countries to end their transitions with a TFR of exactly 2.1 and only a small 
number with a TFR below 2 . Actual trends at the country level will no doubt deviate from projected trends because of unexpected events and unpredictable errors. In addition, the foregoing analysis indicates that there will be some systematic errors. For example, the number of countries with fertility below 2 will almost certainly be higher than the UN projects, and, other things being equal, this would bring the average TFR for 2020-25 below projected levels. However, the UN projections for most countries do not assume a significant deceleration of the pace of fertility decline at the end of the transition as has been observed in the past. This feature implies that actual fertility trends in some countries will be higher than projected. The net result is a set of small positive and negative errors in the projections that will partially offset one another. Since it is not clear whether the positive errors will be larger or smaller than the negative ones, there is no reason to conclude that the UN projections on average are too high or too low over the next quarter-century.

\section{CONCLUSION}

Assuming that the past record of fertility transition will be repeated, at least in broad outline, and assuming continued development, the following trends can be expected in the next few decades:

- The small number of countries that are still pretransitional will likely enter the transition. When this will happen depends on achievement of some socioeconomic progress, but the level of development required for entering the transitions has been dropping.

— Fertility decline will proceed relatively rapidly for countries in the early phases of the transition. The pace of this early decline will be lower in the future because future transitions are expected to start at lower levels of development than in the past. Effective family planning programs assist couples in preventing unplanned pregnancies, and hence speed up a population's progress through the transition.

-As countries approach the later stages of the transition, the pace of decline will slow down. The main reason for expecting this deceleration is that diffusion and social interaction processes accelerated the decline early in the transition. Once this process has largely run its course, fertility late in the transition becomes more closely tied to 
level of socioeconomic development. Rapid fertility decline then usually requires rapid development. Increases in life expectancy and literacy appear to be particularly conducive to fertility decline.

The wide variation in the level and pace of change that has characterized fertility in the past will no doubt be observed in the future. As a consequence, the TFRs of countries in 2025 will likely vary from less than 2 to well above 3. It would not be surprising if fertility in a nontrivial number of developing countries were to stall above replacement for a few decades. Past examples of such a pattern are found in Argentina and Uruguay. These two countries began their transitions in the first half of the twentieth century, and in the 1950s their TFRs had declined to about 3 . Since then fertility has changed very little and was still above 2.5 in 1995-2000. The apparent stalling of fertility in the 1990s in a number of countries with DHS surveys supports this conclusion.

The future course of fertility depends crucially on progress in human development. The recent experience of countries with high levels of development suggests that life expectancy near 75 years combined with literacy near 95 percent is needed on average to approach replacement. A strong commitment to human development can lead to much progress in literacy and life expectancy in a relatively short time. It will be a challenge, however, for many countries to reach these high levels of human development in the next quarter-century. For example, the medium variant of the UN population projections expects unweighted average life expectancy to reach only 69 years in 2020 25 . The UN does not project literacy levels but average literacy will probably fall short of 95 percent. The implication is that average fertility can be expected to remain significantly above replacement until at least 2025 .

This conclusion is consistent with the UN medium variant projections, which expect the unweighted average TFR of all developing countries to decline at a modest pace to 2.8 in 2020-25. Although the preceding analysis has identified factors that will make these projections too high for some countries and too low for others, the average trend for the next quarter-century seems about right. The proportion of developing countries with fertility below 2-currently one in ten-will no doubt rise over time, but it will almost certainly remain substantially less than one-half by $2020-25$. 


\section{Notes}

The author gratefully acknowledges comments on an earlier draft of this paper from John Casterline, Mark Montgomery, Joseph Potter, and Susan Watkins. This paper was made possible through support provided by the Hewlett and Mellon Foundations and by the Office of Population, Bureau for Global Health, U.S. Agency for International Development, under the terms of Award No. HRN-A00-99-00010. The opinions expressed herein are those of the author and do not necessarily reflect the views of these donors.

1 In some countries fertility fluctuated so that the TFR fell below the 5 percent threshold initially but rebounded, before subsequently again dropping below this threshold. For this study the most recent observed year of reaching the 5 percent threshold is used as the transition year.

2 For example, for the post- 1975 period, a country in transition in 1975 contributes four observations with TFRs for 1975-80, 1980-85, 1985-90, and 1990-95 and corresponding pace estimates from $1975-80$ to $1980-85$, from $1980-85$ to $1985-$ 90, from 1985-90 to 1990-95, and from 1990-95 to 1995-2000. The fact that some countries contribute more observations than others could lead to a bias, but this bias is minimized by controlling for the level of the TFR in Figure 2.

3 This finding is consistent with Casterline (2001a), who reported that national fertility declines in the first ten years of the transition proceeded more rapidly in the 1960s than in later decades.

$4 \quad$ Further analysis shows no significant trend since 1975.

5 In countries with more than two surveys in the 1990s, the first and last were used.

6 The percent literate among adults was available only for the period 1970-98. Since this variable changes only slowly over time, estimates were made for the 1960s by logistic backward extrapolation. 
7 Crisis periods are defined as quinquennia during which the change in life expectancy was more than three standard deviations from the average pace of change in life expectancy for all countries and periods.

8 Results are based on fixed-effects regressions with observations limited to years with the lowest levels of each development indicator (life expectancy $<45$, percent literate $<25, \log$ of GDP/capita $<2.7$, percent urban $<10$, and percent of labor force in agriculture $>90$ ).

9 Based on OLS regressions with controls for region (Asia, Latin America, Middle East/North Africa, with sub-Saharan Africa as reference region).

10 OLS regressions of the decline in TFR in the decade after transition onset on the level of development indicators in the year of transition onset (with controls for region) show statistically significant effects for life expectancy, percent literate, and percent in agriculture, but not for GDP per capita and percent urban. OLS regressions of the decline in TFR in the decade after transition onset on the change in development indicators in the same decade (with control for region) show no statistically significant effects for change in life expectancy, literacy, percent in agriculture, and percent urban.

11 The relationship between TFR and the socioeconomic measures is likely to be nonlinear at very high levels of development because fertility cannot continue to fall indefinitely as development proceeds. This issue is not examined further because very few populations have reached this endpoint in the transition.

12 A fixed-effects regression that controls for unobserved country variables and using the same explanatory variables gave very similar results: significant negative effects for life expectancy and literacy; no significant effects for GDP per capita, percent of labor force in agriculture, and the dummy variables for year of observation. The only difference from the OLS results presented in Table 3 is that the effect of percent urban is significant and negative. A test for interactions between development measures and year found no significant effects. 


\section{References}

Bankole, Akinrinola and Charles F. Westoff. 1995. "Childbearing attitudes and intentions," Demographic and Health Surveys, Comparative Studies No. 17. Calverton, MD: Macro International.

Becker, Gary S. 1991. A Treatise on the Family. Enlarged Edition. Cambridge: Harvard University Press.

Bongaarts, John. 1997. "The role of family planning programmes in contemporary fertility transitions," in The Continuing Demographic Transition, Gavin W. Jones, Robert M. Douglas, John C. Caldwell, and Rennie M. D'Souza, eds. Oxford: Clarendon Press, pp. 422-443.

Bongaarts, John. 1999. "The fertility impact of changes in the timing of childbearing in the developing world," Population Studies 53: 277-289.

Bongaarts, John and Griffith Feeney. 1998. "On the quantum and tempo of fertility," Population and Development Review 24(2): 271-291.

Bongaarts, John and Elof Johansson. 2002. "Future trends in contraceptive prevalence and method mix in the developing world," Studies in Family Planning 33(1): 2436.

Bongaarts, John and Robert G. Potter. 1983. Fertility, Biology, and Behavior: An Analysis of the Proximate Determinants. New York: Academic Press.

Bongaarts, John and Susan Cotts Watkins. 1996. "Social interactions and contemporary fertility transitions," Population and Development Review 22(4): 639-682.

Bulatao, Rodolfo A. and John B. Casterline, eds. 2001. Global Fertility Transition. Population and Development Review, Supplement to Vol. 27. New York: Population Council.

Bulatao, Rodolfo A. and Ronald D. Lee, eds. 1983. Determinants of Fertility in Developing Countries. 2 Vols. New York: Academic Press.

Caldwell, John C. 1982. Theory of Fertility Decline. New York: Academic Press.

Caldwell, John C. 2001. “The globalization of fertility behavior," in Global Fertility 
Transition, Rodolfo A. Bulatao and John B. Casterline, eds. Population and Development Review, Supplement to Vol. 27. New York: Population Council, pp. 93-115.

Casterline, John B. 2001a. "The pace of fertility transition: National patterns in the second half of the twentieth century," in Global Fertility Transition, Rodolfo A. Bulatao and John B. Casterline, eds. Population and Development Review, Supplement to Vol. 27. New York: Population Council, pp. 17-52.

Casterline, John B. 2001b. "Diffusion processes and fertility transition: Introduction," in National Research Council, Diffusion Processes and Fertility Transition: Selected Perspectives, John B. Casterline, ed. Washington, DC: National Academy Press, pp. 1-38.

Cleland, John. 2001. "Potatoes and pills: An overview of innovation-diffusion contributions to explanations of fertility decline," in National Research Council, Diffusion Processes and Fertility Transition: Selected Perspectives, John B. Casterline, ed. Washington, DC: National Academy Press, pp. 39-65.

Cleland, John and Christopher Wilson. 1987. "Demand theories of the fertility transition: An iconoclastic view," Population Studies 41(1): 5-30.

Curtis, Siân L. and Katherine Neitzel. 1996. "Contraceptive knowledge, use and sources," Demographic and Health Surveys, Comparative Studies No. 19. Calverton, MD: Macro International.

Demeny, Paul. 1997. "Replacement-level fertility: The implausible endpoint of the demographic transition," in The Continuing Demographic Transition, Gavin W. Jones, Robert M. Douglas, John C. Caldwell, and Rennie M. D’Souza, eds. Oxford: Clarendon Press, pp. 94-110.

Easterlin, Richard A. 1975. "An economic framework for fertility analysis," Studies in Family Planning 6(3): 54-63.

Henry, Louis. 1961. “Some data on natural fertility,” Eugenics Quarterly 8: 81-91.

Heston, Alan, Robert Summers, Daniel A. Nuxoll, and Bettina Aten. 1995. "The Penn World Tables (PWT) version 5.6." (http://datacentre.chass.utoronto.ca/pwt/ ). Updated from Robert Summers and Alan Heston, "The Penn World Table (Mark 5): 
An expanded set of international comparisons, 1950-1988, " Quarterly Journal of Economics, May 1991, pp. 327-368.

Knodel, John and Etienne van de Walle. 1979. "Lessons from the past: Policy implications of historical fertility studies," Population and Development Review 5(2): $217-245$.

Kohler, Hans-Peter. 2001. Fertility and Social Interaction: An Economic Perspective. New York: Oxford University Press.

Lutz, Wolfgang, ed. 1996. The Future Population of the World: What Can We Assume Today? Revised edition. London: Earthscan Publications.

Montgomery, Mark R. and John B. Casterline. 1996. "Social learning, social influence, and new models of fertility," in Fertility in the United States: New Patterns, New Theories, John B. Casterline, Ronald D. Lee, and Karen A. Foote, eds. Population and Development Review, Supplement to Vol. 22. New York: Population Council, pp. 151-175.

National Research Council. 2000. Beyond Six Billion: Forecasting the World's Population, John Bongaarts and Rodolfo A. Bulatao, eds. Committee on Population, Commission on Behavioral and Social Sciences and Education. Washington, DC: National Academy Press.

National Research Council. 2001. Diffusion Processes and Fertility Transition: Selected Perspectives, John B. Casterline ed. Committee on Population, Commission on Behavioral and Social Sciences and Education. Washington, DC: National Academy Press.

Notestein, Frank W. 1953. "Economic problems of population change," in Proceedings of the Eighth International Conference of Agricultural Economists. London: Oxford University Press, pp. 13-31.

Sen, Amartya. 1999. Development as Freedom. New York: Knopf.

Tsui, Amy Ong. 2001. "Population policies, family planning programs, and fertility: The record," in Global Fertility Transition, Rodolfo A. Bulatao and John B. Casterline, eds. Population and Development Review, Supplement to Vol. 27. New York: Population Council, pp. 184-204. 
United Nations. 1998. World Population Prospects: The 1996 Revision. New York: United Nations Population Division.

United Nations. 1999. Levels and Trends of Contraceptive Use as Assessed in 1998. New York: Department for Economic and Social Affairs, United Nations Population Division.

United Nations. 2001. World Population Prospects: The 2000 Revision. New York: United Nations Population Division.

U.S. Census Bureau. 1999. World Population Profile: 1998. Washington, DC: Department of Commerce.

Watkins, Susan Cotts. 1986. "Conclusions," in The Decline of Fertility in Europe, Ansley J. Coale and Susan Cotts Watkins, eds. Princeton: Princeton University Press, pp. $420-449$.

Watkins, Susan Cotts. 1987. "The fertility transition: Europe and the Third World compared," Sociological Forum 2(4): 645-673.

World Bank. 2000. World Development Indicators, 2000. Washington, DC: World Bank. 


\title{
POLICY RESEARCH DIVISION WORKING PAPERS
}

\author{
Recent Back Issues
}

133 Mary Arends-Kuenning and Sajeda Amin, "The effects of schooling incentive programs on household resource allocation in Bangladesh."

134 John Bongaarts and Charles F. Westoff, "The potential role of contraception in reducing abortion."

135 John B. Casterline and Steven W. Sinding, "Unmet need for family planning in developing countries and implications for population policy."

*136 Carol E. Kaufman, Thea de Wet, and Jonathan Stadler, "Adolescent pregnancy and parenthood in South Africa."

*137 Valerie L. Durrant and Zeba A. Sathar, "Greater investments in children through women's empowerment: A key to demographic change in Pakistan?"

138 Sajeda Amin, Alaka Malwade Basu, and Rob Stephenson, "Spatial variation in contraceptive use in Bangladesh: Looking beyond the borders."
139 Geoffrey McNicoll, "Managing population-environment systems: Problems of institutional design."

140 Barbara S. Mensch, Barbara L. Ibrahim, Susan M. Lee, and Omaima ElGibaly, "Socialization to gender roles and marriage among Egyptian adolescents."

141 John Bongaarts and Elof Johansson, "Future trends in contraception in the developing world: Prevalence and method mix."

142 Alaka Malwade Basu and Sajeda Amin, "Some preconditions for fertility decline in Bengal: History, language identity, and an openness to innovations."

143 Zeba Sathar, Cynthia B. Lloyd, Cem Mete, and Minhaj ul Haque, "Schooling opportunities for girls as a stimulus for fertility change in rural $\mathrm{Pa}-$ kistan." 
144 John Bongaarts, "Household size and composition in the developing world."

145 John B. Casterline, Zeba A. Sathar, and Minhaj ul Haque, "Obstacles to contraceptive use in Pakistan: A study in Punjab."

146 Zachary Zimmer, Albert I. Hermalin, and Hui-Sheng Lin, "Whose education counts? The impact of grown children's education on the physical functioning of their parents in Taiwan."

147 Philomena Nyarko, Brian Pence, and Cornelius Debpuur, "Immunization status and child survival in rural Ghana."

148 John Bongaarts and Zachary Zimmer, "Living arrangements of older adults in the developing world: An analysis of DHS household surveys."

149 Markos Ezra, "Ecological degradation, rural poverty, and migration in Ethiopia: A contextual analysis."
150 Cynthia B. Lloyd, Sahar El Tawila, Wesley H. Clark, and Barbara S. Mensch, "Determinants of educational attainment among adolescents in Egypt: Does school quality make a difference?"

151 Barbara S. Mensch, Paul C. Hewett, and Annabel Erulkar, " The reporting of sensitive behavior among adolescents: A methodological experiment in Kenya."

152 John Bongaarts, "The end of the fertility transition in the developed world."

153 Mark R. Montgomery, GebreEgziabher Kiros, Dominic Agyeman, John B. Casterline, Peter Aglobitse, and Paul Hewett, "Social networks and contraceptive dynamics in southern Ghana."

154 Paul C. Hewett and Mark R. Montgomery, "Poverty and public services in developing-country cities." 
155 Zachary Zimmer, Linda G. Martin, and Ming-Cheng Chang, "Changes in functional limitations and survival among the elderly in Taiwan: 1993, 1996, and 1999."

156 John Bongaarts and Griffith Feeney, "How long do we live?"

157 Zachary Zimmer and Sovan Kiry Kim, "Living arrangements and socio-demographic conditions of older adults in Cambodia."

158 Geoffrey McNicoll, "Demographic factors in East Asian regional integration."
159 Carol E. Kaufman, Shelley Clark, Ntsiki Manzini, and Julian May, "How community structures of time and opportunity shape adolescent sexual behavior in South Africa."

160 Julia Dayton and Martha Ainsworth, "The elderly and AIDS: Coping strategies and health consequences in rural Tanzania."

161 John Bongaarts, "The end of the fertility transition in the developing world." 


\section{The End of the Fertility Transition in the D eveloping World}

John Bongaarts

2002 No. 161 